\title{
Investigation of Teacher Support and Teacher Training During the COVID-19 Pandemic: Tools and Skills Moving the Classroom Forward
}

\author{
Wannaprapha Suksawas $^{1} \&$ Sita Yiemkuntitavorn ${ }^{1}$ \\ ${ }^{1}$ Sukhothai Thammathirat Open University, Thailand \\ Correspondence: Wannaprapha Suksawas, Sukhothai Thammathirat Open University, Thailand.
}

Received: November 27, 2021

Accepted: December 20, 2021

Online Published: December 24, 2021

doi: 10.5539/elt.v15n1p118

URL: https://doi.org/10.5539/elt.v15n1p118

\begin{abstract}
Teaching remotely from home is now compulsory for lecturers as schools across the globe have closed due to the COVID-19 pandemic. A marriage of technology and teacher training is required to help educators deliver lessons effectively online. This research aimed to 1) investigate the type of technological support teachers need to teach online during and after the COVID-19 pandemic; 2) identify the type of teacher training needed during and after the pandemic; and 3) assess teachers' satisfaction towards their training in relation to their needs. This study utilized a mixed methods research design and included a sample of 59 teachers studying for a Master's degree in Curriculum and Instruction, majoring in English language at an open university in Thailand. Data were analyzed using the Statistical Package for the Social Sciences (SPSS) to compute means and standard deviations. In addition, qualitative data derived from a questionnaire were analyzed using typological analysis. The research findings showed: 1) the "fundamental technologies" teachers need for online teaching include computers or other computing devices, a reliable and stable-as-possible internet connection, a microphone, and a headset and camera; and 2) the task of implementing engaging lessons online and supporting students to use ICTs for projects or class work placed particular training demands on teachers. Specifically, they required: (1) training to build knowledge of the basic functions for undertaking virtual teaching and learning; (2) access to meaningful and relevant content to create lessons for students, and (3) online worksheets and projects for students.
\end{abstract}

Keywords: teacher support, tertiary level, COVID-19 pandemic

\section{Rationale and Objectives of the Study}

The global outbreak of COVID-19 in late 2019 has meant that teachers and students around the world have had to adjust to a new 'normal' in the teaching and learning environment. In response to the outbreak, governments of many countries have ordered nationwide school closures as an emergency measure to mitigate the spread of the virus. Teachers are now required to engage in online teaching in response to the disruption to classrooms and 'normal' face-to-face interactions with students. The disruption has interfered with teachers' instructional plans and has presented many challenges to the learning processes that traditionally occur in classroom settings. Thailand has not been exempted from the impact of such disruptions to its schools. COVID-19 was first detected in Thailand in January 2020 (Ministry of Public Health, 2020, February 14). In turn, the steady increase of confirmed cases has resulted in educational institutions being temporarily closed to support home-based isolation and implementation of the Thai Government's physical distancing policy (Prime Minister Office, 2020, March 26).

At present, "Many schools are showing support for increased levels of technology in the classroom by providing fundamental technologies, enhancing internet connection, and implementing programs designed to improve computer literacy for both teachers and students" (Johnson, Jacovina, Russell, \& Soto, 2016, p. 1). Over the years, language teachers have become increasingly familiar with the use of technology-enhanced teaching practices such as blended learning and the flipped classroom. Technology is used as supplementary or additional tools to promote student participation in their learning in addition to face-to-face interactions with teachers and their peers. Studies claim that learning technologies provide many positive affordances to the language classroom. Indeed, according to Rahman (2015), "Students are more responsive, spontaneous and co-operative in the technological advanced classroom as the lessons become hands on and lively" (Rahman, 2015, p. 3). 
Enjoyable classrooms with technology can increase the students' motivation to learn about the subject. In language classrooms specifically, those that integrate technology have been shown to produce positive results (Almekhlafi, 2020). Flipped classroom is an instructional strategy that reverses the traditional learning environment by delivering instructional content, often online, outside of the classroom to provide students with a more personalized way of learning (Suo \& Hou, 2017, p. 62).

However, the shift from traditional classroom-based learning to online learning in response to the COVID-19 pandemic is a completely new experience for teachers. Indeed, it has presented language teachers with a number of challenges; for example, ensuring their readiness and the readiness of students to teach and learn online, developing their ICT knowledge and skills, accessing online teaching-learning tools, and implementing online teaching techniques effectively. These challenges have resulted in a substantial change in teachers' cognition of online teaching (Borg, 2015, 2019; Gao \& Lawrence, 2020). Teachers must learn to present content to students online in their own ways. The traditional classroom interaction dynamic is also missing. Moreover, different types of content must be delivered to accommodate the different learning styles of students. All these issues influence the online engagement of students and their learning outcomes (Lawson \& Lawson, 2013; Rosen, Glennie, Dalton, Lennon, \& Bozick, 2010) Johnson et al. (2016) reported the challenges related to integrating technology for learning in the classroom were related to three main areas: access, training, and support. The study showed that many schools and students do not have adequate access to computers and internet connections, teachers lacked professional training on how to use the technologies most effectively, and technical and administrative support was often inadequate. These issues can restrict the effectiveness of online teaching. Moreover, Wang, Zhang, Zhao, and Jiang (2020) have asserted that a significant effort from administrative systems is vital in mitigating the effects of emergency online instruction on student learning outcomes.

Recent studies have been conducted on learner and teacher readiness for online education during the COVID-19 pandemic (e.g. Dhawan, 2020; Kanchai, 2021; Mahyoob, 2020; Oraif \& Elyas, 2021). In addition, there have been investigations of students' levels of acceptance for using online learning platforms (Moonma, 2021). However, little has been reported on the challenges language teachers face and the types of support they need to teach effectively online during the crisis. This study was undertaken to help fill this gap and provide insights into the English language teaching situation in Thailand. The findings are expected to help government sectors, school administrators, teachers, and the designers of learning materials to understand frontline language teachers' needs when teaching online. The research questions underpinning this study are:

1) What types of "fundamental technologies" do teachers need to teach online during and after the COVID-19 pandemic?

2) What topics do teachers need training or professional development on to help them to overcome their challenges?

3) To what extent were the teachers satisfied with the training provided in relation to their needs?

\section{Framework}

To properly investigate the technologies and training that language teachers need to be effective online practitioners, it is essential to study the contextual factors affecting their cognition of online education and actual classroom practices. In the field of teacher education, studies related to teacher cognition and their actual classroom practices have been conducted extensively. This is because factors such as the teacher's beliefs, knowledge, theory of teaching, attitude, access to materials, and instructional methods typically inform her or his classroom practices (e.g. Borg, 2015; Burns, Freemand, \& Edwards, 2015; Gao, 2019; Zhan \& Jiang, 2021). The present study adopted the elements and processes in Borg's (2015, p. 333) language teacher cognition model (see Figure 1) as its conceptual framework. This is because the model captures the potential factors related to teacher cognition; namely, schooling, professional coursework, and context that directly impacts the classroom practice.

Figure 1 shows that factors such as teacher knowledge and skills related to online teaching subject matter knowledge, access to online materials, and awareness of online activities can cause teacher cognition of online teaching to change. Moreover, the actual classroom practices of teachers are affected by the interaction between their cognition and the prevailing contextual factors. As a consequence, teacher cognition is one of the major factors contributing to the successful implementation of online classes. This presents study attempted to investigate how the in-service teachers' cognition in regard to their beliefs, knowledge, attitude, subject matter, materials affect their actual online classroom practice. The framework helps to inform the question items in the questionnaire and interview questions of the present study to highlight on the mentioned aspects in teachers' cognition. 


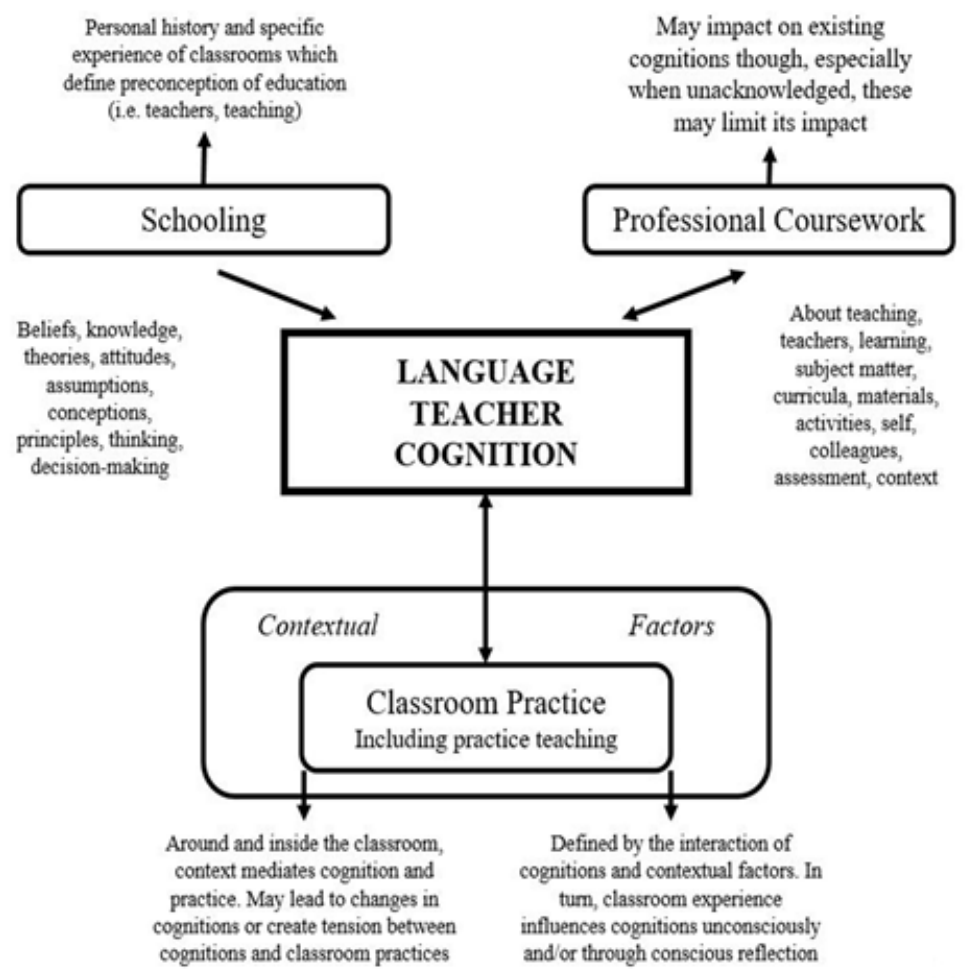

Figure 1. Elements and process in language teacher cognition (taken from Borg, 2015, p. 333)

In addition to the elements affecting teacher cognition, the questionnaire was designed to investigate teachers' needs in regard to online teaching. Consideration was given to the input, process, and output elements of current online learning so as to provide appropriate feedback on the entire process as shown in Figure 2 below. Input included national policy, institutional policies, organizational management, professional support, material support, online pedagogy, and instructional plans reflecting the current online teaching situation. Current online instruction includes contemporary teaching practices, communication with students, assessment, and student support. Output elements of online instruction comprise student learning outcomes, student satisfaction, teacher satisfaction, and stakeholder benefits. Finally, the data on output inform the feedback provided on the process. Although the online curriculum analysis framework below did not inform all question items in the questionnaire, it helped the researchers to design questionnaire to find out online materials in the input, online instruction in the process and teachers' satisfaction in the output. These eventually helped researchers to provide feedback to the online pedagogy. 


\section{Input \\ Process \\ Output}

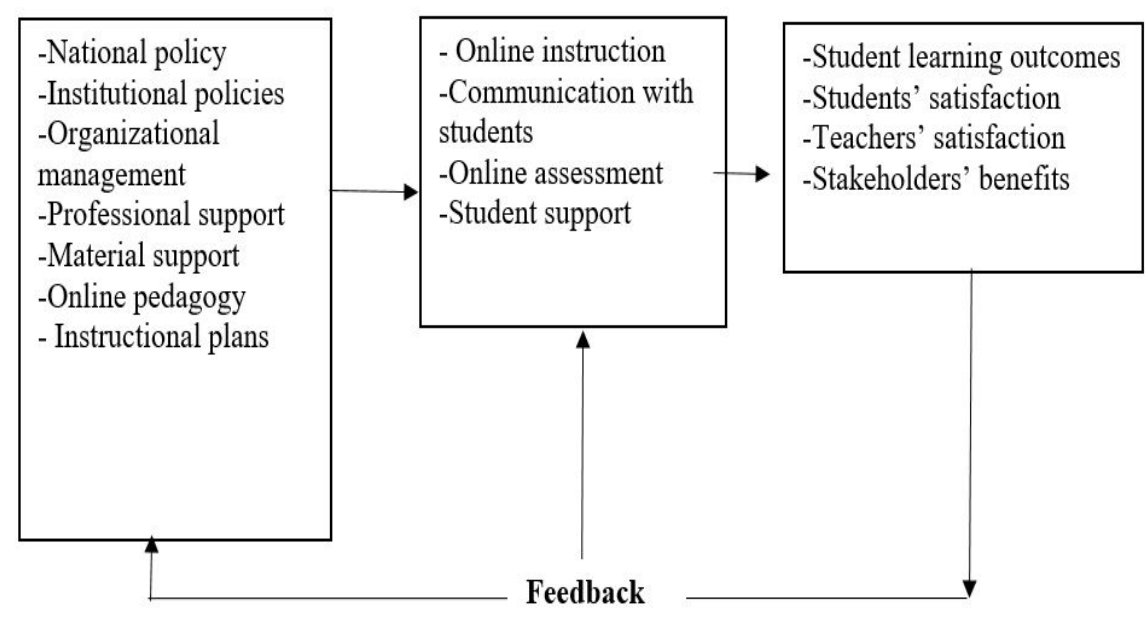

Figure 2. Online curriculum analysis framework

\section{Methods}

This study included a sample of 59 in-service teachers from different parts of Thailand. All teachers were completing a Master's degree in Curriculum and Instruction, majoring in English language, at an open university in Thailand. The sample was originally 60 participants, but one participant withdrew from the project due to health problems.

During phase I of the study the teacher participants were first asked to identify which technologies they utilized in their teaching on a weekly basis. Their responses were recorded on a Likert Scale ranging from 1 (not at all) to 5 (extremely high). In this phase, the participants were also asked to respond to open-ended questions about the provision of teacher training on online teaching in relation to their perceived needs. By definition, open-ended questions are broad and can be answered in detail. The design of the questionnaire was reviewed by three experts. In addition, to assess the content validity of the research instrument, the Index of Item-Objective Congruence (IOC) was used based on the score range from -1 to +1 . The IOC points were rated and reached a high-level value of 0.8407 . The IOC points calculations provided a rating for the congruency of the items as follows: Congruent $=+1$, Questionable $=0$, Incongruent $=-1$.

Items receiving scores lower than 0.5 were revised. Conversely, items receiving scores higher than or equal to 0.5 were preserved. Regarding the reliability of the questionnaire, this was assessed via a pilot test with 15 in-service language teachers who were not in the sample group. Following consideration of the feedback from the pilot test group and some minimal changes based on their suggestion, the questionnaire was distributed online to the study sample using the Google Form platform.

After collecting and reviewing the questionnaire data, the participants were asked to volunteer to participate in a focus group interview using MS teams to explain their responses and provide further comments on their problems and needs. Quantitative data from the questionnaire were analyzed using SPSS to compute means and standard deviations. In addition, qualitative data derived from the questionnaire and focus group interview were analyzed using typological analysis.

The researchers then designed a training program based on an analysis of the data from phase I of the study. The training program was part of phase II of the study and aimed to equip the teachers with both the content knowledge and the technological skills they required for online teaching. Specifically, the 'Successful online teaching' training program was established to develop the participating teachers' English online teaching skills. As such, the program focused on developing their knowledge and understanding of different teaching aspects including content for teaching integrated skills in English, grammar and content-based subjects, methods for developing different activities for implementation in an online classroom as well as a variety of approaches to assessing and evaluating students' English language skills. The training program consisted of 12 hours of online training (Microsoft Teams) divided into two focus areas: English language teaching principles (6 hours); and basic functions of virtual learning, using online activities to promote student participation, and creating online worksheets and online assessments (6 hours). The training was designed to develop the participants' knowledge, 
skills, and attitude around online teaching. Therefore, the behavioral objectives of the training were set as follows:

\section{1) Knowledge (Cognitive Domain)}

i. Match content knowledge on English instruction with a suitable teaching text.

ii. Explain concepts related to methods of teaching English skills and content.

iii. Choose online classroom activities and assessment and evaluation approaches that match English skills, grammar, and content subjects.

iv. Design appropriate online instructional plans.

2) Skills (Psychomotor Domain)

i. Increase skills in designing online instructional plans.

ii. Increase online teaching skills.

3) Attitude (Affective Domain)

i. Have a positive attitude and a commitment to continuous professional development.

ii. Be confident in teaching online.

Following the training program, the participants reported their level of satisfaction towards the organized training. A five-point Likert-scale was used with $1=$ totally unsatisfied and $5=$ totally satisfied.

\section{Results and Conclusions}

\subsection{Participants' Demographic Data}

This section presents the participants' demographic data to provide a general overview of their background characteristics. This helps to illuminate the results of the quantitative and qualitative data analyses in this study. The majority of respondents identified as female $(85 \%$; male $=15 \%)$. They were mainly from the Central $(30 \%)$ and Southern regions of Thailand (30\%) followed by the North-East (23.33\%), East (6.67\%), and Northern (10\%) regions. No respondents were from the Western region of Thailand. As evidenced by the dispersed locations of the respondents, students enrolled at an open university experience education delivery in a way different from students attending a specific higher education institution. Students enrolled at an open university derive from different locations and are required to demonstrate a higher degree of self-directed learning. Therefore, the data gathered does not represent a specific location in Thailand, but rather provides a general picture of in-service teachers' online teaching experiences and needs across Thailand more broadly.

Respondents' age ranges were, from most represented to least represented: 26-30-years-old (63.3\%), 31-35-years-old (11.6\%), 41-45-years-old (11.6\%), 36-40 years old (10\%), and 20-25 years old (3.33\%). They also varied in their years of teaching experiences: 0-5 years (56.6\%), 5-10 years (25\%), 11-15 years (8.33\%), more than 10 years $(10 \%)$. Based on the respondents' age ranges and years of teaching experience, it can be concluded that most participants were in the early stage of their career and may need professional training in terms of language teaching content and technology tools. Lastly, most respondents were teaching in primary schools $(51.6 \%)$, followed by secondary schools $(30 \%)$, vocational institutions $(13.3 \%)$, and then tertiary institutions (5\%). This informs the design of the training to ensure it suits the participants' needs in terms of teaching principles, tools, activities, and online assessment approaches suitable for young EFL learners. The respondents' teaching areas are also relevant to the design of the training program. The results revealed that most respondents were teaching integrated skills $(66.63 \%)$, followed by grammar $(13.3 \%)$, content-based subjects $(10 \%)$, speaking $(5 \%)$, listening $(1.6 \%)$, reading $(1.6 \%)$, and writing $(1.60 \%)$.

When designing an online training program to facilitate effective online language teaching, designers need to account for both the students' ability levels and the different ways to teach integrated skills, grammar, and content-based subjects successfully online. The respondents' current online teaching platforms included Google Meet (28.30\%), Zoom (18.30\%), Google Classroom (16.6\%), Microsoft Teams (8.33\%), Line Messenger (18.30\%), and Facebook Messenger (6.60\%). The teachers' access to various general technology platforms for online teaching including Google Classroom, Google Meet, Zoom, and Microsoft Teams indicates the support they received from their organization during the crisis. Some respondents also used private social media channels as online teaching tools such as Line Messenger and Facebook Messenger. This may reflect a lack of support from the administration department, a lack of teacher skills on how to use more complex online classroom platforms, or a lack of student access to the more formal platforms. 
In terms of the school affiliation, most respondents were from the Office of the Basic Education Commission (71.6\%) followed by the Office of the Vocational Education Commission (13.3\%), Office of the Private Education Commission (10\%), and the Ministry of Higher Education, Science, Research and Innovation (5\%). The school affiliation results show the main support channels for teachers from the schools that shut down.

The following section presents the findings to emerge from the data analysis in relation to the study's two research questions. Descriptive statistics are presented first derived from the questionnaire results for: technological support needs (topic 1-3), and professional training areas that language teachers need (topic 4-6).

Table 1. Statistics analysis from the questionnaire

\begin{tabular}{|c|c|c|c|c|c|c|}
\hline & Topic 1 & Topic 2 & Topic 3 & Topic 4 & Topic 5 & Topic 6 \\
\hline Valid & 59 & 59 & 59 & 59 & 59 & 59 \\
\hline Missing & 1 & 1 & 1 & 1 & 1 & 1 \\
\hline Mean & 4.7119 & 4.2712 & 4.0847 & 4.0000 & 4.1186 & 4.1695 \\
\hline Std. Error of Mean & .06419 & .10491 & .12858 & .12792 & .13260 & .12363 \\
\hline Median & 5.0000 & 4.0000 & 4.0000 & 4.0000 & 4.0000 & 4.0000 \\
\hline Mode & 5.00 & 5.00 & 5.00 & 5.00 & 5.00 & 5.00 \\
\hline Std. Deviation & .49308 & .80581 & .98765 & .98261 & 1.01853 & .94964 \\
\hline Variance & .243 & .649 & .975 & .966 & 1.037 & .902 \\
\hline
\end{tabular}

The data presented in Table 1 include the mean scores for each of the six topics to assist with understanding the results for the first and second research questions as follows:

\subsection{Answer for Research Question 1}

1). What types of "fundamental technologies" do teachers need to teach online during and after the COVID-19 pandemic?

The first research question relates to topics 1-3 and the basic technologies teachers need most when teaching online during the pandemic. The first three topics in Table 1 above presents the mean scores of their needs as follows. Topic 1: Computers and other computing devices was 4.71 (highest level need), Topic 2: A reliable and stable internet connection was 4.27 (high level need), and Topic 3: A microphone, headset and camera was 4.08 (high level need). When discussing the mean scores from the questionnaire with the participants during the focus group interview, they revealed that they needed computers and other computing devices, a reliable and stable-as-possible internet connection, a microphone, and a headset and camera to teach online at a high and highest level. This suggests an unreadiness among the language teachers to teach online because of their lack of fundamental technologies for conducting online lessons. In turn, unreadiness and unpreparedness to teach online have the potential to cause language teachers to experience anxiety and stress in a prolonged pandemic situation.

Topic 1: Computers and other computing devices

Table 2. Participants' responses in relation to topic 1

\begin{tabular}{llllll}
\hline & & Frequency & Percent & Valid Percent & Cumulative Percent \\
\hline \multirow{4}{*}{ Valid } & 3.00 & 1 & 1.7 & 1.7 & 1.7 \\
& 4.00 & 15 & 25.4 & 25.4 & 27.1 \\
& 5.00 & 43 & 72.9 & 72.9 & 100.0 \\
& Total & 59 & 100.0 & 100.0 & \\
\hline
\end{tabular}

As shown in Table 2, most participants (72.9\%) indicated 'extremely high' as their response regarding the need for computer hardware, followed by $25.4 \%$ and $1.7 \%$ of participants who indicated their level of need as 'high' or 'medium', respectively. This result aligns with the finding reported by Rattanakhamfu (2020) that "compared to countries around the world, only $21 \%$ of Thai households have computers, which is lower than the global average of $49 \%$ and the developing countries' average of 38\%." This result also aligns with the finding by (Wei, 2015 , p. 45 ) that just $28.7 \%$ of Thai households have access to a computer at and just $22.7 \%$ of Thai households have access to the Internet. The lack of computers in Thai households presents a serious challenge to online teaching and learning when the teachers are forced to use this mode of instruction. Studies conducted in Indonesia (Atmojo \& Arif, 2020; Pasaribu \& Dewi, 2021; Situmorang, Pramusita, \& Nugroho, 2021) report similar results and thus also share this concern. In addition, the teachers indicated during the focus group interview that they typically used the desktop computers at their education institution. One participant 
commented, "It was kind of awkward at the beginning, setting up a main 'classroom' at home". Another teacher remarked, "If schools can't provide a desktop computers or a tablet, I have to use my old version laptop and my smartphone."

Topic 2: A reliable and stable-as-possible Internet connection

Table 3. Participants' responses in relation to topic 2

\begin{tabular}{llllll}
\hline & & Frequency & Percent & Valid Percent & Cumulative Percent \\
\hline \multirow{4}{*}{ Valid } & 2.00 & 1 & 1.7 & 1.7 & 1.7 \\
& 3.00 & 10 & 16.9 & 16.9 & 18.6 \\
& 4.00 & 20 & 33.9 & 33.9 & 52.5 \\
& 5.00 & 28 & 47.5 & 47.5 & 100.0 \\
& Total & 59 & 100.0 & 100.0 &
\end{tabular}

Table 3 reveals that $47.5 \%$ and $33.9 \%$ of participants responded with 'extremely high' and 'high', respectively to indicate their level of need for a reliable and stable-as-possible Internet connection. The teachers indicated during the focus group interview that they have an Internet connection which they use for their own activities, but when it was to be used for school administrative and teaching tasks, this presented a different scenario. One teacher stated that she had to maximize the speed of the service, and another commented that the data availability on her mobile phone was not adequate to sustain whole lessons. In addition, the teachers indicated an awareness that not every student had access to the Internet or to the equipment necessary to do the assigned tasks.

Topic 3: A microphone, headset and camera

Table 4. Participants' responses in relation to topic 3

\begin{tabular}{llllll}
\hline & & Frequency & Percent & Valid Percent & Cumulative Percent \\
\hline \multirow{6}{*}{ Valid } & 1.00 & 1 & 1.7 & 1.7 & 1.7 \\
& 2.00 & 3 & 5.1 & 5.1 & 6.8 \\
& 3.00 & 11 & 18.6 & 18.6 & 25.4 \\
& 4.00 & 19 & 32.2 & 32.2 & 57.6 \\
& 5.00 & 25 & 42.4 & 42.4 & 100.0 \\
& Total & 59 & 100.0 & 100.0 &
\end{tabular}

As shown in Table 4, 42.4\% and 32.4\% of participants responded with 'extremely high' or 'high', respectively to indicate their level of need for other 'technology' such as a microphone, headset and camera to conduct online teaching effectively. Most laptops are equipped with a camera, speakers, and a microphone, however they may not always be suitable for use as they can pick up external noise, create echo, and produce howl-round. During the focus group interview, one teacher commented, "A pair of headphones or in-ear headphones with a microphone will help online teaching. However, for the desktop computers, they don't have any built-in webcams. Teachers need to install one for online teaching."

\subsection{Answer for Research Question 2}

2). What topics do teachers need training or professional development on to help them to overcome their challenges?

The second research question relates to topics $4-6$ and the perceived training requirements by the language teachers. Topic 4: Training on basic functions of virtual learning

Table 5. Participants' responses in relation to topic 4

\begin{tabular}{llllll}
\hline & & Frequency & Percent & Valid Percent & Cumulative Percent \\
\hline \multirow{6}{*}{ Valid } & 1.00 & 1 & 1.7 & 1.7 & 1.7 \\
& 2.00 & 1 & 1.7 & 1.7 & 3.4 \\
& 3.00 & 19 & 32.2 & 32.2 & 35.6 \\
& 4.00 & 14 & 23.7 & 23.7 & 59.3 \\
& 5.00 & 24 & 40.7 & 40.7 & 100.0 \\
& Total & 59 & 100.0 & 100.0 & \\
\hline
\end{tabular}


Table 5 shows that $40.7 \%$ and $32.2 \%$ of participants, respectively responded with 'extremely high' and 'high' to indicate their need for training on the basic functions of virtual learning including live video recording, audio recording, chat activities (for live Q\&A), editing, and video publishing to improve their online lectures. Live video and live streaming functions in particular were regarded as very useful for distance learning but were also new for many teachers. Teachers not only had to take the time to learn how to conduct online lessons during the COVID-19 pandemic, they were also required to learn how to record, save, and upload the lesson for students who may have missed the session or who want to go back and review parts of the lesson. Nevertheless, in order to bring the live-streaming classroom to life, educational establishments need to invest in proper video streaming software.

Topic 5: Training on how to create engaging online activities

Table 6. Participants' responses in relation to topic 5

\begin{tabular}{llllll}
\hline & & Frequency & Percent & Valid Percent & Cumulative Percent \\
\hline \multirow{6}{*}{ Valid } & 1.00 & 2 & 3.4 & 3.4 & 3.4 \\
& 2.00 & 2 & 3.4 & 3.4 & 6.8 \\
& 3.00 & 9 & 15.3 & 15.3 & 22.0 \\
& 4.00 & 20 & 33.9 & 33.9 & 55.9 \\
& 5.00 & 26 & 44.1 & 44.1 & 100.0 \\
& Total & 59 & 100.0 & 100.0 &
\end{tabular}

Table 6 shows $44.1 \%$ and 33.9\% of participants responded with 'extremely high' and 'high', respectively to indicate their level of need for training on how to create engaging online activities. Some teachers indicated during the focus group interview that it was very difficult to encourage students to participate in and engage with the online activities they had created. One teacher commented that students have different learning styles and preferences, meaning the onus is on the teacher to provide multiple learning pathways. Moreover, one of the biggest challenges for teachers in the online learning situation is managing student distractions. Teachers must make use of different content and learning materials to minimize distractions and keep students engaged in the lesson (Atmojo \& Arif, 2020; Murphy, 2020). Two teachers commented that while technology-based games can be used to support teaching and learning, they still needed to take what makes playing games fun and engaging and adapt these affordances to promote student learning.

Topic 6: Training on how to create online worksheet and assessment

Table 7. Participants' responses in relation to topic 6

\begin{tabular}{llllll}
\hline & & Frequency & Percent & Valid Percent & Cumulative Percent \\
\hline \multirow{6}{*}{ Valid } & 1.00 & 1 & 1.7 & 1.7 & 1.7 \\
& 2.00 & 1 & 1.7 & 1.7 & 3.4 \\
& 3.00 & 13 & 22.0 & 22.0 & 25.4 \\
& 4.00 & 16 & 27.1 & 27.1 & 52.5 \\
& 5.00 & 28 & 47.5 & 47.5 & 100.0 \\
& Total & 59 & 100.0 & 100.0 &
\end{tabular}

Lastly, Table 7 reveals that $47.5 \%$ and $27.1 \%$ of participants responded with 'extremely high' and 'high', respectively to indicate their level of need for training and professional development on how to create online worksheets and projects for students along with how to conduct online assessments of student learning outcomes. Some remarked in the focus group interview that they had to learn how to convert PDFs into interactive online activities for students. Participants also reported that conducting online assessments was a big challenge for them because some aspects of the students' learning progress and outcomes were best assessed through observations of their participation in learning projects rather than through the use of online tests. Creating online projects and promoting online interactions among students, especially younger aged students, were therefore areas that the language teachers indicated they needed training on.

The results from this study suggest that Thai teachers need access to basic 'technologies' to support online teaching during and after the COVID-19 pandemic. In addition, they require additional training in multiple areas to support students to achieve the desired learning outcomes. These findings raise an important question about 
the type of training teachers need and therefore what teacher education programs should be doing to adequately prepare teachers for online instruction during and after COVID-19. At private schools in Thailand, training teachers to be effective online practitioners has mainly been the responsibility of the employer.

Following the collection and analysis of the questionnaire and focus group interview data, the researchers implemented phase II of the study. After receiving information from teachers' cognition in regard to beliefs, knowledge, attitude, subject matter, and teaching materials, the researchers designed a 12-hour training program for the participants to help them to overcome the challenges they were experiencing when conducting online teaching. The training was conducted through Microsoft teams; a platform all participants were familiar with having participated in online seminars using this platform during their Master's degree program due to the COVD-19 pandemic. The program involved 6 hours of training on the principles of online English language teaching and 6 hours of training on the basic functions of virtual learning, using online activities to promote student participation, and creating online worksheets and online assessment activities. At the conclusion of the training program the participants were asked to provide feedback on the extent to which they were satisfied with the training provided and the outcomes they achieved. This data (feedback) was collected to assist trainers to make informed decisions on how to improve the program in the future as well as to answer the third research question of the study:

\subsection{Answer for Research Question 3}

$3)$. To what extent were the teachers satisfied with the training provided in relations to their needs?

The third research question can be answered by summarizing the participants' reported levels of satisfaction towards the training according to four domains: Content and Activities, Speakers, Understanding, and Knowledge Application. A summary of the satisfaction survey items and result is shown in Table 8.

\section{a). Content and Activities}

Participants rated their satisfaction towards the content and activities of the training program at the highest level for all the items in this category. The item to rate at the highest level of satisfaction overall was 'usefulness of the training' $(4.71 \%)$, followed by feeling 'more confident teaching online after the training' $(4.63 \%)$, and the usefulness of the 'online assessments' (4.61\%).

b). Speakers

Participants rated their satisfaction with the speakers at the highest level across all items in this category. The item to rate at the highest level was their ability to 'clearly pass on knowledge' $(4.73 \%)$ followed by their ability to explain the content of the program (4.66\%).

c). Understanding

Participants demonstrated more knowledge of English online instruction at the conclusion of the training program than at its commencement $(2.07 \%)$. They rated their satisfaction with their after-training knowledge at the 'high' level (4.31\%).

\section{d). Knowledge Application}

Participants rated their satisfaction with their confidence to apply the knowledge they gained from the training program at the high level $(4.27 \%)$. In terms of their perceived ability to pass on their new knowledge, they rate this at the 'high' level (4.27\%) also.

Table 8. Participants' level of satisfaction towards the training program and outcomes

\begin{tabular}{llll}
\hline Items & $\overline{\mathbf{X}}$ & S.D. & results \\
\hline Content and Activities & & & \\
1. The content and activities were suited the participants' needs. & 4.56 & 0.50 & highest \\
2. The content was suitable to develop the knowledge of the training participants. & 4.61 & 0.49 & highest \\
3. The training activities helped participants to gain more insights into and & 4.58 & 0.50 & highest \\
understanding of the content. & & & \\
4. The content was useful for the participants. & 4.71 & $0.46 \quad$ highest \\
5. The participants were more confident teaching online after the training. & 4.63 & 0.49 highest \\
6. Online programs and online assessments suggested were useful for the 4.61 & 0.49 highest
\end{tabular}
participants. 


\section{Speakers}

7. The speakers could clearly pass on knowledge.

$\begin{array}{lll}4.73 & 0.45 & \text { highest } \\ 4.61 & 0.49 & \text { highest } \\ 4.61 & 0.49 & \text { highest } \\ 4.66 & 0.48 & \text { highest } \\ 4.59 & 0.50 & \text { highest }\end{array}$

8. The speakers could explain the content.

9. The connection between the topics in the training was clear.

10. The training content was completely explained and included.

\section{Understanding}

12. Knowledge and understanding before training.

$\begin{array}{lll}2.07 & 0.58 & \text { low } \\ 4.31 & 0.68 & \text { high }\end{array}$

13. Knowledge and understanding after training.

\section{Knowledge Application}

14. Be able to apply the knowledge gained from the training into work practice.

$\begin{array}{lll}4.27 & 0.45 & \text { high } \\ 4.27 & 0.45 & \text { high }\end{array}$

15. Be able to disseminate / pass on the knowledge.

The results shown in the Table 8 indicate that the participants overall were satisfied with the training program provided and the outcomes they achieved. While some commented that the duration of the training period was limited, they, nonetheless, regarded the training as useful to them for teaching online in an emergency context.

In addition to being to the participants' satisfaction, the researchers found that the training objectives were met across all three domains: cognitive, psychomotor, and affective. Regarding the cognitive domain, participants demonstrated the ability to: match content knowledge on English instruction with suitable teaching texts; explain the concepts related to English skills and content instruction; choose online classroom activities and assessment and evaluation approaches that match English skills, grammar and content subjects; and design appropriate online instructional plans. Regarding the psychomotor domain, following their participation in the workshop sessions the participants demonstrated improved skills at designing online instructional plans and implementing online teaching practices. Lastly, regarding the affective domain, during the training and workshop sessions the participants reflected on their positive attitude and commitment to continuous professional development and of feeling more confidence in teaching online. In turn, confidence in teaching online is a major focus of this study based on the researchers' beliefs that in-service teacher cognition of online teaching can move the online classroom forward successfully because it reflects how they conduct their online lessons in reality.

\section{Recommendations}

Future studies may consider taking the findings of this study to create a teacher training course that responds to language teachers' needs in more detail, over longer hours, and with more workshops. Larger groups of respondents may provide more insights into the needs of teachers, especially those teaching in remote areas in Thailand or in other countries with EFL programs. The investigation of teachers' technological knowledge (TK), pedagogical knowledge (PK), and content knowledge (CK) - as part of the Technological Pedagogical Content Knowledge (TPACK) framework - after receiving training support is also beneficial to reconfirm the success of the support and professional training provided (Mishra \& Koehler, 2006). Government sectors and school administrators need to consider how to support teachers during the COVID-19 pandemic so as to help them to successfully achieve the set learning goals and objectives. If the teachers are confident in their online teaching practice, this may mitigate the effects of the pandemic on students' learning outcomes.

\section{References}

Almekhlafi, A. G. (2020). Designing and creating digital interactive content framework: Description and Evaluation of the Almekhlafi digital interactive content model. Science Education International, 31(2), 130-141. https://doi.org/10.33828/sei.v31.i2.1

Atmojo, A. P., \& Arif, N. (2020). EFL classes must go online! Teaching activities and challenges during COVID-19 pandemic in Indonesia. Register Journal, 13(1), 49-76. https://doi.org/10.18326/rgt.v13i1.49-76

Borg, S. (2015). Teacher cognition and language education: Research and practice. London, England: Bloomsbury.

Borg, S. (2019). Language teacher cognition: Perspectives and debates. In L. X. Gao (Ed.), Second handbook of English language teaching. Speinger, Cham. https://doi.org/10.1007/978-3-030-02899-2_59 
Burns, A., Freemand, D., \& Edwards, E. (2015). Theorizing and studying the language-teaching mind: Mapping research on language teacher cognition. The Modern Language Journal, 99(3), 585-601. https://doi.org/10.1111/modl.12245

Dhawan, S. (2020). Online Learning: A panacea in the time of COVID-19 crisis. Journal of Educational Teachnology Systems, 49(1), 5-22. https://doi.org/10.1177/0047239520934018

Gao, L. X. (2019). Teacher cognition and practice in classroom listening instruction: Case studies of five English-as-a- Foreign-Language (EFL) teachers in a Chinese university. ( $\mathrm{PhD}$ thesis). The University of Auckland, Auckland, New Zealand.

Gao, L. X., \& Lawrence, J. Z. (2020). Teacher learning in difficult times: Examining foreign language teachers' cognitions about online teaching to tide over COVID-19. Frontiers in Psychology, 11, 1-14. https://doi.org/10.3389/fpsyg.2020.549653

Johnson, A. M., Jacovina, M. E., Russell, E. D., \& Soto, C. M. (2016). Challenges and solutions when using technologies in the classroom. In S. A. Crossley \& D. S. McNamara (Eds.), Adaptive Educational Technologies for Literacy Instruction. New York: Routledge. https://doi.org/10.4324/9781315647500-2

Kanchai, T. (2021). EFL teachers' ICT literacy acquisition to online instruction during COVID-19. LEARN Journal: Language Education and Acquisition Research Network Journal, 14(2), 282-312.

Lawson, M. A., \& Lawson, H. A. (2013). New conceptual frameworks for student engagement research, policy, and practice. Review of Educational Research, 83(3), 432-479. https://doi.org/10.3102/0034654313480891

Mahyoob, M. (2020). Challenges of e-Learning during the COVID-19 pandemic experienced by EFL learners. Arab World English Journal, 11(4), 351-362. https://doi.org/10.24093/awej/vol11no4.23

Ministry of Public Health. (2020, February 14). Public health emergency response action plan for COVID-19 and roles of relevant agencies. Retrieved from https://ddc.moph.go.th/viralpneumonia/eng/file/pub_doc/LDoc9.pdf

Mishra, P., \& Koehler, M. J. (2006). Technological pedagogical content knowledge: A framework for integrating technology in teachers' knowledge. Teachers College Record, 108(6), 1017-1054. https://doi.org/10.1111/j.1467-9620.2006.00684.x

Moonma, J. (2021). Google classroom: Understanding EFL students' attitude towards its use as an online learning platform. English Language Teaching, 14(11), 38-48. https://doi.org/10.5539/elt.v14n11p38

Murphy, M. P. (2020). COVID-19 and emergency eLearning: Consequences of the securitization of higher education for post-pandemic pedagogy. Contemporary Security Policy, 41(3), 492-505. https://doi.org/10.1080/13523260.2020.1761749

Oraif, I., \& Elyas, T. (2021). The impact of COVID-19 on learning: Investigating EFL learners' engagement in online courses in Saudi Arabia. Education Sciences, 11(3), 1-22. https://doi.org/10.3390/educsci1 1030099

Pasaribu, T. A., \& Dewi, N. (2021). Indonesian EFL Students' voices on online learning during COVID-19 through appraisal analysis. LEARN Journal: Language Education and Acquisition Research Network Journal, 14(1), 399-426.

Prime Minister Office. (2020, March 26). Declaration of an emergency situation in all areas of the Kingdom of Thailand. Retrieved from https://www.mfa.go.th/main/contents/files/news3-20200326-161207-994002.pdf

Rahman, T. (2015). Challenges of using technology in secondary English language classroom (Master Degree of Arts in TESOL). BRAC University, BRAC University. Retrieved from https://core.ac.uk/download/pdf/61807266.pdf

Rattanakhamfu, S. (2020). Covid-19 emphasizes the need to bridge the digital divide and reduce online educational inequality. Retrieved from https://tdri.or.th/en/2020/05/covid-19-emphasizes-the-need-to-bridge-the-digital-divide-and-reduce-online-e ducational-inequality/

Rosen, J. A., Glennie, E. J., Dalton, B. W., Lennon, J. M., \& Bozick, R. N. (2010). Noncognitive skills in the classroom: New perspectives on educational research. RTI Press publication No. BK-0004-1009. Research Triangle Park, NC: RTI International. https://doi.org/10.3768/rtipress.2010.bk.0004.1009 
Situmorang, K., Pramusita, S. M., \& Nugroho, Y. D. (2021). English teachers' reflections and lessons learned in language teaching during COVID-19 pandemic. Journal of English Education and Development, 50(1), 50-61. https://doi.org/10.31605/eduvelop.v5i1.1111

Suo, J., \& Hou, X. (2017). A study on the motivational strategies in college English flipped classroom. English Language Teaching, 10(5), 62-67. https://doi.org/10.5539/elt.v10n5p62

Wang, G., Zhang, Y., Zhao, J., \& Jiang, F. (2020). Mitigate the effects of home confinement on children during the COVID-19 outbreak. The Lancet, 395(10228), 945-947. https://doi.org/10.1016/S0140-6736(20)30547-X

Wei, S. J. (2015). Thailand industralization and economic catch-up. Country diagnostic study Mandaluyong City, Philippines: Asia Development Bank.

Zhan, J., \& Jiang, L. (2021). Language teacher cognition: A sociocultural perspective. ELT Journal, 75(1), 122-124. https://doi.org/10.1093/elt/ccaa061

\section{Copyrights}

Copyright for this article is retained by the author(s), with first publication rights granted to the journal.

This is an open-access article distributed under the terms and conditions of the Creative Commons Attribution license (http://creativecommons.org/licenses/by/4.0/). 